\title{
Nepalese Schoolchildren as Research Participants: Challenges in Qualitative Research
}

\author{
Ghanshyam Bishwakarma \\ University of Eastern Finland Joensuu Campus, Joensuu, Finland \\ Email: bishwaka@student.uef.fi,ghanshyam.bishwakarma@gmail.com
}

How to cite this paper: Bishwakarma, G. (2017) Nepalese Schoolchildren as Research Participants: Challenges in Qualitative Research. Open Journal of Social Sciences, $\mathbf{5}$, 52-68.

http://dx.doi.org/10.4236/jss.2017.51005

Received: December 7, 2016

Accepted: January 10, 2017

Published: January 13, 2017

Copyright $\odot 2017$ by author and Scientific Research Publishing Inc. This work is licensed under the Creative Commons Attribution International License (CC BY 4.0).

http://creativecommons.org/licenses/by/4.0/

\section{(c) (i) Open Access}

\begin{abstract}
The present research explores the potential methodological challenges in conducting qualitative fieldwork using schoolgirls in Nepal as participants. It particularly focuses on the logistic, academic, and social challenges that impact on the scholarly inquiry into aspects of schooling and the wider society in rural Nepal. The participants in this study were schoolgirls, and school dropouts girls (12 - 16 years old), from Dalit community in Nepal. Schoolchildren, both in school and school drop-outs particularly girls, are an invaluable source of information on society and schooling. Although school-aged girls have the right to express their views, perceptions, opinions, and competencies, as much as adults do. However, their participation in research activities has been very rare in Nepal. This research applies various methodological tools to carry out this qualitative study in the school setting in Nepal and highlights the challenges associated with these methodologies, particularly the challenges related to confidentiality and interactions when using children as research participants.
\end{abstract}

\section{Keywords}

Methodological Challenge, Schoolchildren, Qualitative Research, Dalit, Nepal

\section{Introduction}

Research is a continuous process that consumes both time and energy. England (1994) claimed, "Research is a process, not just a product" (p. 82) [1]. Conducting research can be exciting but also very stressful, frustrating, and problematic. Carrying out research with children can be especially difficult during observation, conversation, negotiation, and participation. However, doing the research with children is also helpful in understanding what they think about the issues 
that are impacting them. However, the research with the children should balance the objectives of the study with the wellbeing and safety of the children. The researchers can ensure security and respect of the participating children by taking appropriate actions and providing the right support to them. Specifically, the researchers need to consider how to acquire the informed consent. They also need to know what to do with the collected data or information to the research and how to manage the risk of any harm to the participant children in the research. Schoolchildren are an integral and distinct component of society and are widely considered to be the future-makers of a country. As such, participating in social activities within the community is a child's right. However, as Deatrick [2] pointed out, "[School] children have traditionally been excluded from personally participating in research as they have been considered to be too immature" [2]. This is specifically because of the ethical and methodological issues. During the research schoolchildren, can lose and gain a lot. The research and study can bring the rights abuse of the children. Unintentionally most often the researchers ignore the rights of the children during the research. When the children appear as the victims of the tragedy and without their consent are involved in the clinical research, this causes the violation of their human rights. Research incorporating the schoolchildren has many potential drawbacks and benefits. It is quite crucial to enhance the attention towards the ethical issues that take place during the research involving the children.

Over the last few years, scientific research incorporating children as participants has grown tremendously. Scott (2000) [3] remarked, "The construction of childhood that views children as immature adults is coming under attack, and there is a new demand for research that focuses on children as actors in their right" (p. 98). The formal research and investigation incorporating the children have contributed to the construction of the information providing the researchers and scientists with the brilliant knowledge of behaviour and minds of children as well as the generalisation of the knowledge. There are several ways to achieve the knowledge and several methods of conducting the research incorporating the children. The research of the researchers and their conclusions can protect and promote the children rights as well. In the vast field of social sciences, the research involving children has also been advantageous in the history. However, it is necessary for the researcher to recognise the school child participating in the research to identify the difference between a child and an adult (Mahat, 2011) [4].

Research involving schoolchildren has been increasing in Nepal as well. This study also attempts to examine the relationship between the researcher and the research participants, in the context of the gender and community practices; in this instance, the collaboration between of a young male researcher and schoolgirls as participants, both representing the same community group in Nepal. The schoolgirls, partaking in this study belong to the Dalit community in Nepal. The term Dalit in Nepal commonly refers to a caste of socially excluded and disadvantaged group of people, who are discriminated against due to their caste identity, 
and faces practices of "untouchability" within the society.

Nepalese society is still very much a patriarchal one, guided by strict norms and societal values on caste and gender systems. As a result, girls are faced with multiple forms of, discrimination, humiliation, oppression, exclusion, exploitation, and unequal treatment, in every social sphere. This is particularly pronounced for Dalit girls (Jagaran Media Centre, 2012) [5]. Therefore, exploring and overcoming challenges presented by the present research process, in involving a male researcher from the same community as its young female participants, is a unique and exciting undertaking in Nepal. The condition of the women in Nepali society cannot be considered good and safe. Almost $60 \%$ of the women in Nepal are illiterate (UNESCO, 2011) [6]. The girls in Nepal are not provided much of the opportunities. The women's status in Nepal varies according to castes, religion, economy, and structure of the community. The girls of the higher castes normally get more opportunities and facilities. The girls belonging to the lower castes are never provided with the facilities and opportunities. They also have fewer opportunities for freedom, education, and employment. There are no factors for the encouragement of the women. The caste system is very much responsible for the inequality in the gender. The women belonging to the different religions make them undergo various restrictions and limitations.

A vast and growing body of literature discusses the merits and challenges of conducting fieldwork in sociology research involving subjects who are of the same gender, race, or ethnicity as the researcher. Researcher and participant demographics present sensitive and serious issues (Zavella, 1993: p. 138) [7]. Zavella (1993) argued, "Being a member of a subordinated group under study carries particular problems and creates personal and ethical dilemmas for social scientists on the basis of their race, ethnicity, gender, political sympathies, or even personal foibles" (p. 139).

As a Nepali researcher based in a university abroad, but conducting fieldwork in two districts of Nepal, the Hill, and Terai regions, I had mixed experiences. Being a member of the marginalised Dalit community, I have an established network of key personnel among Dalit activists and scholars in Nepal. Therefore, it was convenient for me to find a local research assistant who could help me both logistically and academically in the field. Furthermore, people, in general, were receptive to providing any assistance required by me during fieldwork. Also, I had familiarity due to previous work experience in the Terai and Hill regions and possessed a good working knowledge of the local languages. These factors contributed immensely in gaining easy access to the field sites in both areas. However, accessing field sites was only the beginning of the research process.

I also faced some negative experiences while conducting fieldwork. On several occasions, people suspected me of representing the interests of a Non-Governmental Organization or an International Non-Governmental Organization. I had to spend considerable time and energy to clarify and convince and them otherwise. In addition, I had limited social connections with the village and 
villagers (schoolgirls, teachers, and parents) in both research sites due to my own background. I was born and raised in Pokhara city where I was schooled, and subsequently attended college also in Pokhara and Kathmandu. After a few years of working in Nepal, I migrated abroad for further education. All these factors contributed to my inability to connect fully within a social setting of the village and the villagers at the research sites. This gap, at times, made it challenging to reintegrate into village life and with the day to day social activities particularly within the relatively short timeframe of the research. Integrating with the younger generation, i.e. the schoolchildren at both research sites seemed especially challenging.

This academic paper is divided into five sections. The section one- briefly provides the background to my research; introduces research aims and explains the objectives and motivation of research. Furthermore, it also clarifies the significances of the study. Section two explores the social and cultural issues related to schooling and caste and gender inequality in Nepal. It attempts to show rigidity of social and cultural fabric through a different lens. Section-three mainly highlights the methodological tools-participants' observation, interviews, and focus group discussions that I used while in the fieldwork. Furthermore, I also highlighted some reflections on my position in the entire fieldwork. The section four is about the discussion which discusses the potential challenges that occurred while conducting fieldwork. Lastly, section five provides the conclusion of the study which shed light on this current research with schoolchildren from Dalit community in Nepal.

\section{Social and Cultural Consideration: A Nepalese Perspective}

Nepal, one of the least developed countries in the world, is a mountainous landlocked country sandwiched between two of the most populous nations in the world, India, and China. Nepal is a culturally, socially, religiously, linguistically diverse country with a population of 28.2 million and comprising an area of 147,181 square kilometres. The culture of Nepal presents the fusion of TibetoMongolian and Indo-Aryan influences because of a brief history of trade, conquest, and migration. The population of Nepal comprises of cultural racial and linguistic groups and is often divided into three broad groups. These include Tibeto-Nepalese, Indo-Nepalese, and indigenous Nepalese.

Historically, education in Nepal was based primarily on home-schooling, particularly for elite families and their relatives. Post-1951, with democracy being established in the country, schooling was made available to the public. However, Dalits continued to be restricted in accessing education. Currently, Education in Nepal continues to develop regarding integrating modern information technology and inclusive policies within the classroom.

Nepal is a multicultural and multi-ethnic country profoundly affected by social hierarchy and patriarchy systems. Such practices impact upon the existing education system as well, where discrimination, marginalisation, and social inequality based on social class, status, caste, gender, ethnicity, and religion 
represent critical aspects. During my visits to both research sites, I found that most Dalit girls are ignored and silenced by the society. Current research shows some progress in education in Nepal. For example, the literacy rate in Nepal increased substantially from 51.4 percent in 2001 to 65.9 percent in 2011 . However, education for a marginalised community group, Dalit, continues to be at the lower end [8]. This particularly represents the vast majority of girls from the Dalit community in Nepal who are still illiterate.

According to United Nations (UN, 2007), girls' enrollment in primary schools in Nepal reached 87.4 percent, but enrollment is much lower at the lower secondary and secondary levels, 49.6 percent and 32.8 percent, respectively. In contrast, boys' enrollment stood at 90.7 percent at the primary level, 56.1 percent at the lower secondary level, and 37.7 percent at the secondary level (UN, 2007). As these figures indicate, although the girls' enrollment rate at the primary level is high, their dropout rate is higher among girls, due to various factors.

In recent years, school education has become a growing concern and a key challenge for the educational policymakers and researchers worldwide. The United Nations Educational, Scientific, and Cultural Organization (UNESCO) has been leading a global movement to provide quality education for every child, youth, and adult. Most countries adopt free and compulsory basic education to achieve their development goals.

The system of formal education, particularly school education, in Nepal is complex and consists of different types of schools: private schools, public schools, community schools, and religious schools. The process explored in this article is based on public schools which represent the majority of schoolchildren in Nepal. Students attending public schools in Nepal have comparatively fewer resources and fewer opportunities than children in other schools including teachers who are not suitably qualified. Children attending public schools come from different social and cultural backgrounds. Most schoolchildren, particularly those from poor economic backgrounds, minorities, Dalits, are compelled to attend public schools, where fewer facilities, qualified teachers, and educational resources are available.

Previous research has reported social discrimination based on caste and gender within the schools and the wider society (Bishwakarma, 2010; Stash et al., 2001) [8] [9]. Furthermore, cultural and social activities also affect the overall schooling process.

Gender discrimination has been the problematic issue for enhancing the equality and acquiring the human rights particularly for children in Nepal. Historically, a patriarchal system of the social relations is preferred in Nepal. This preference tends to negatively impact the education right of the girls in Nepal as well as health opportunities. There is also less investment in the education of the girls in Nepal. There are three critical factors responsible for that. Firstly, the girls are believed to leave their biological house after getting married, and this makes the parents and the society think that they do not deserve to get an education. Secondly, non-farm work is believed to be not appropriate for the women. 
Thirdly, the females are more required for the farm work.

The socio-cultural practices and the attitude of parents do not favour the girls in getting the education in the Nepalese society. The girls inside the household usually get an unequal distribution of care and facilities regarding health services, nutrition which leads to higher mortality and malnutrition. Again, the discriminatory practices are the reason behind this inequality. This inequality is deeply rooted in the Nepalese society. This unequal treatment leads to the subordinate position of the women in the Nepalese society. The discrimination like the early marriage, viewing the girl as the property of others and the son preference limits the enrolment of girls in the educational institutes, and their attendance is also impacted in case they get the chance of getting an education. This additionally undermines the significance of the education of girls in Nepal.

There are some psychological barriers to the education of girls in Nepal as well. Schools are not always girl friendly specifically in Nepal. They have failed to protect the safety and privacy of the girls. Many schools in Nepal even don't provide separate toilets for the girls. The girls do not attend school in Nepal because of this reason. Another issue is the absence of the female teachers in the schools of Nepal. The parents never feel safe sending their girls to the school where there is no female teacher and consist of just male teachers. They also believe that sending their girls to such school may result in the sexual abuse of the boys as well as teachers. Educating the young girls does include a high risk in a male-only school atmosphere.

Nepalese society and culture follow and dictates traditional social norms and values, especially regarding male-female relationships. The Dalit community, although a part of Nepalese society, is not considered to be "pure" from the cultural perspective. Therefore, the combination of being a member of Dalit community, a young male researcher, and an outsider, presented a significant set of challenges for me in speaking with schoolgirls freely and comfortably for the purpose of data collection, even after receiving written permission from the parents, teachers, and the children themselves.

Allowing a male researcher to conduct qualitative interviews with schoolgirls in the school setting and interpret accounts of the participants' lives, is a contentious concept within feminist literature. However, some feminist researchers also openly welcome male researchers who can contribute to research with and about women (Wilkinson \& Kitzinger, 1996) [10].

Qualitative research methods have been widely used, and scientifically accepted, in childhood research. Qualitative research stresses the socially constructed nature of reality and the situational constraints that shape the inquiry, creating an intimate relationship between the researcher and the participants (Denzin \& Lincoln, 2000: p. 8) [11]. Concerning children, Clark (2011) [12] acknowledged that "Qualitative research creates an opportunity for them to communicate by setting up a child relevant input for theorising and understanding the child's experiences" (p. 12). However, qualitative research methods present numerous inherent challenges, particularly when schoolchildren are the key 
respondents. One notable aspect of qualitative researchers is that social scientists tend to be more interested in real-life situations and, for this reason, will carry out "natural experiments" utilising events that occur naturally but interrupt the normal course of life (Woods, 1999) [13]. The current study examines the qualitative methods that have been used to analyse children as respondents in school settings and the challenges that accompany the use of these methods.

Qualitative methods of research should promote children's rights as participants in research. Furthermore, researchers must acknowledge children as equal partners, and eliminate the power imbalances that typically exist between children and adults (Kanyal, 2014) [14]. As Clark (2011) [12] observed, a childcentered inquiry is meant to focus on the children's ways of experiencing different features of their environments through child-sensitive observation and witnessing (p. 16). Most researchers explore various available methods before deciding on the most suited approach to conducting research efficiently and reliably. Scott (2000) [3] emphasised that researchers must take into account "the wide range of cognitive and social development that depends primarily on age but also on the gender, socio-economic background, and ethnicity of the child" (p. 101). Considering these factors, my research provided an opportunity for some girls from the Dalit community to express their often-unheard voices. Most of them spoke easily and comfortably on issues of gender and caste inequality, and on their schooling, and therefore, broke the stereotypical image of silenced and ignored Dalit girls.

I conducted three months of ethnographic fieldwork in the autumn and winter of 2014-2015 in the Baglung and Saptari districts, representing the Hill and Terai regions of Nepal, respectively as shown in Figure 1. I selected two public high schools comprising a large representation of Dalit children. Although the total number of students in both schools was large, I chose to interview 12 schoolgirls and 12 drop-outs (both groups 12 - 16 years in age) in total. Six schoolgirls were selected from each school to represent each of the two groups. For added reassurance for the participants, and to ensure the collection of valid data, I enlisted the assistance of a local female research assistant as a mediator. She provided a useful link between the local schoolchildren and the academic paradigm during all fieldwork sessions.

Studying schoolchildren, particularly from a rural area of Nepal, is both logistically and geographically challenging. Additionally, the health and safety issues, language barriers, social and cultural differences also impact in conducting fieldwork. Furthermore, given that Nepal is a country with diverse geography, poor infrastructure with limited road accessibility made it difficult to reach villages, especially in hilly areas due to the lack of drivable roads. It took me around 4 hours to travel from the district headquarters to the field site in Baglung, a hilly district in Nepal. The challenge of the trip itself highlights the difficulties faced by communities living in the hills. Their situation is further exacerbated during winter, when the temperature falls below $5^{\circ} \mathrm{C}$, a major problem in the context of rural Nepal. 


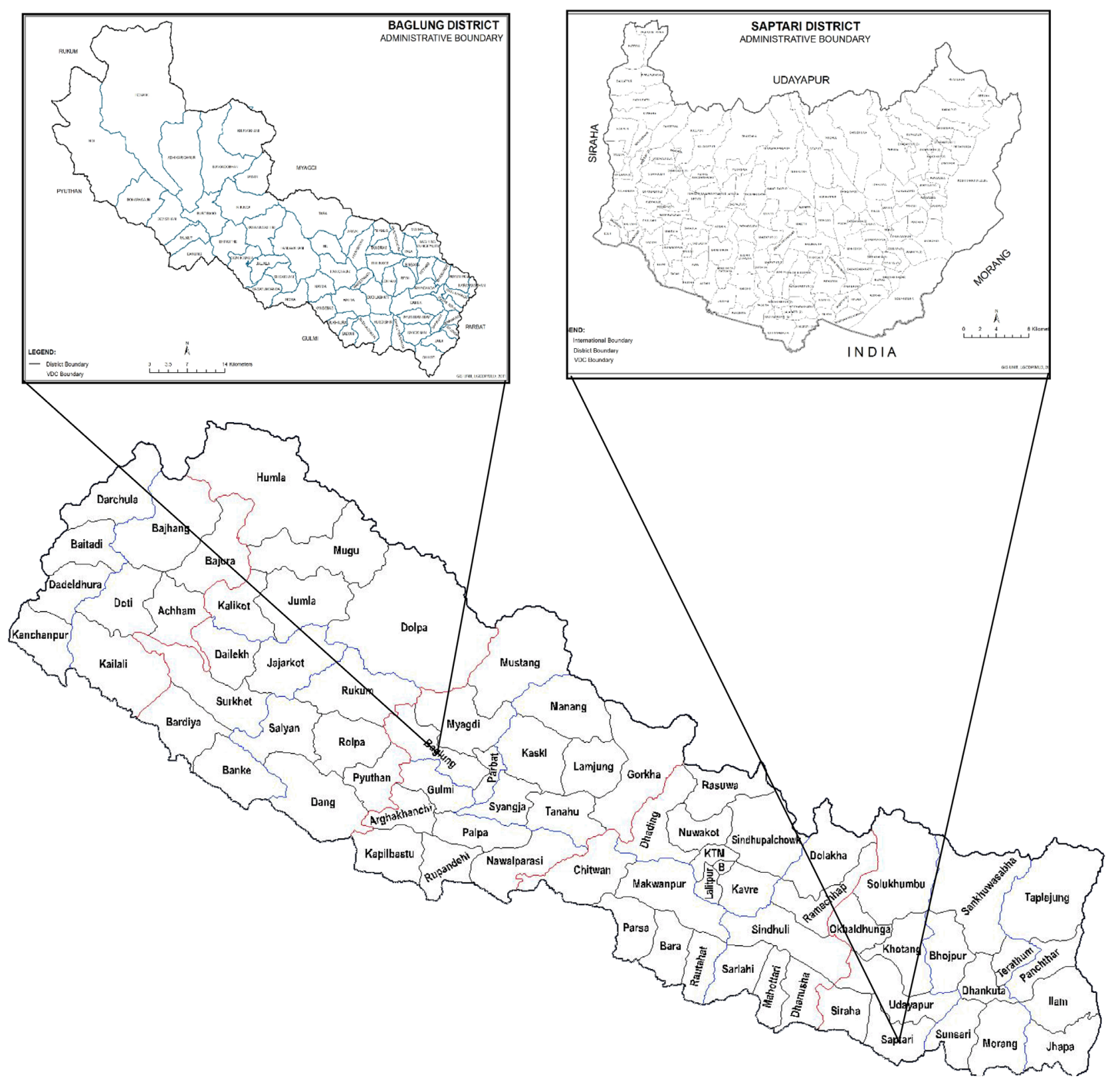

Figure 1. Maps of Nepal and Baglung and Saptari districts in the caption.

I was also faced with difficulties in maintaining regular communications due to lack of sufficient electricity load and Internet access. My communications were primarily dependent on frequent phone calls and e-mail exchanges that I made with local social workers whom I acquainted through "the snowball technique". The pre-arrangement of fieldwork with local social workers in light of no prior financial contributions was also difficult, although some local social workers kindly volunteered for this task, their efforts for the sake of Dalit children. Obtaining parental permission to talk with schoolchildren was equally difficult. I visited the villages during the crop-harvesting season, and most parents were busy in the field. Talking with parents was, therefore, a lengthy process. Most of the children were also busy, either caring for their younger siblings at home or 
helping their parents in the field.

The schoolgirls selected for the study had to devote a certain amount of their time for the interviews and at times became bored and tired. Most of them were shy and nervous during our first meeting, even though I was already familiar with them following my observation period (of a few days). However, consequently, after a few days of visiting the schools, making daily class observations, participating in school activities, and talking with teachers and other school staff, the selected girls were more approachable and ready to talk freely and openly. I conducted the formal interviews with the participants at the end of the designated timeframe for each field site.

\section{My Position in the Fieldwork}

A substantial amount of literature highlights the impact of a researcher's position on their research; their background, beliefs, academic credentials, and values can influence the results of a study. Recent research has raised these topical issues in the context of Nepal as well.

Within the culturally rigid society in Nepal, my role as a male researcher coming from the same community as my participants, addressing issues of gender and caste inequality, and schooling was a highly challenging one. Therefore, I enlisted the help of a local female research assistant throughout my fieldwork. Being transparent about a researcher's position during fieldwork with schoolchildren is considerably a new practice in Nepal. Local researchers coming from foreign universities are taken more seriously in Nepal, particularly in rural communities. I realised that sharing my personal experiences on caste-based discrimination, the patriarchal social system, and the practices of "untouchability", encouraged the participants to share their experiences freely during the interviews and focus group discussions conducted.

Nepal is considered a developing country and many Nepalese children are unable to complete their primary education. A large number of children drop out of school, mostly at the primary and secondary levels. Conducting research on education in Nepal, especially those that focus on schoolgirls, can be difficult due to the existing social and cultural norms, practices, and beliefs. Also, children of a low-caste also face numerous difficulties. For instance, they are not allowed to enter the house of a person of a high-caste, public temples, or public programs. In this context, Dalit girls face even further oppression than boys. As a consequence, Nepalese cultural norms and values discourage girls from participating in public programs, including research studies. Therefore, girls require additional efforts of reassurance regarding establishing trust, encouragement, and friendship in order to encourage participation in research such as the present study. However, although Nepalese are culturally reticent in nature, most of them are comfortable in expressing their views freely once a trustworthy relationship is established. As such, I paid close attention to ensure that the girls can express their views openly during the process of research.

Often, schoolchildren in Nepal expect gifts or tokens from outsiders that visit 
their community, particularly from those visiting from abroad, and local officials from NGOs and INGOs. In keeping with this practice, and as a token of compensation for their time and effort, I distributed some items of stationery (e.g. pencils and paper), to all the girls who participated directly in the interviews and other sessions. The girls who were not directly involved in my research also expected small tokens or trinkets as gifts and raised their voices in the request. This is a common phenomenon in the rural villages of Nepal (Mahat, 2011) [4].

The general expectation of rewards of the community was also a significant challenge in conducting fieldwork. Respondents and their parents were more interested in how I would help them than answering my questions. It was demanding to convince them that I was a doctoral student, originally from western Nepal, and the purpose of my visit was to complete fieldwork for a research study. On some instances, I had to support my statements with documented evidence obtained from my current university.

\subsection{Participant Observation in the School Setting}

Participant observation is one of the key methodological approaches in qualitative research. In this approach, researchers aim to visit the participants as much as possible allowing them to observe and participate in the participants' social activities so that first-hand data related to the participants could be collected within their natural setting (Hume, 2004: p. xi-xxviii) [15]. In keeping with this approach, I actively took part in the various programs that facilitated interaction with the participants besides the general classroom sessions in the schools. I felt that repeated involvement in such activities contributed to strengthening my relationship with the schoolchildren. However, I was cautious in maintaining a strictly professional interaction at all times. Furthermore, I was able to gain perspectives both as an insider of the group as well as an outsider. I was conscious that, by being a member of the same community group as the participants I could be biased while gathering the data.

Participant observation is particularly suited to conducting research with schoolchildren. Observation plays a crucial part in understanding a child's abilities and development. They are the systematic and meticulous study of occurrences with the purpose to perceive the nature and extent of interrelated elements within complex social phenomena (Sharma, 2008) [16]. School ethnographic observations usually focus on interaction and the social order of educational settings. In this study, I explored the impact of the caste and gender order in schoolchildren in Nepal.

Many features of children's interactions and cultures are produced and shared in the present and cannot be easily obtained through interviews and surveys (Corsaro \& Fingerson, 2006) [17]. Corsaro and Fingerson (2006) [17] explained that ethnography involves prolonged fieldwork where the researcher identifies a group of participants and completes profound observation for a prolonged period.

Observing children in their everyday environments enables a researcher to evaluate events with real emotional significance for children, providing a link 
between emotion and cognition that would otherwise be unavailable (Dunn, 2005: p. 87) [18]. Dunn (2005) states that observation of children in their natural settings provides evidence on a child's real life experiences and his or her reactions to those experiences in school and at home (p. 88) [18]. However, results obtained through observation greatly influence a researcher's results; particularly the responses gathered from younger children.

At the beginning of my fieldwork, I conducted multiple visits to the school for casual observation both in the classroom and around the school, to minimise both power relation and social distance between the schoolchildren and the researcher. The unequal power relation between schoolchildren and adult researcher may pressurise school children to answer the question immediately and correctly during conversation (Punch, 2002) [19]. In contrast, by minimising the social distance between these two parties, the participants are encouraged to express their individual views, opinions, and perceptions freely and comfortably. Therefore, I tried to be as casual as possible in my approach, which helps both the researcher and the participants to engage socially with ease and comfort.

One of the primary objectives of carrying out multiple visits to the schools is to observe the actual environment of the setting: of the students, teachers and the whole school in general. This is particularly important in the context of Nepal, where school administrations routinely pressurise their students and teachers to demonstrate their best performance both in education as well as other criteria to impress the outsiders (visitors) that wish to evaluate the overall progress of the school. In such instances, the students and staff are usually pre-informed. However, such practices were prevented due to my frequent visits, and I could observe the natural and real situations of the school setting [20].

I used classroom and teaching practices as the main sources for observation. I collected data both by observing the class when in session, and their interactions within the classroom. These reflect the norm of the classroom. However, although, the observation was of a natural setting in the classroom, observing unobtrusively was a difficult task for me. It is usual that outsiders - such as myself, particularly from the city or abroad, attract more attention while performing any task which could in turn automatically hamper the classroom and daily class activities.

Taking field notes is one method of data collection applied during the current study. Field notes are meant to capture the social, cultural, and natural phenomena being studied. However, taking field notes in a school setting is slightly different from other situations. Although there is no official consensus on what field notes must include, the time and place of events should always be recorded. During the fieldwork for this research, I carried a notebook with me at all times so that I could readily keep records of new ideas and information that emerged during the research process.

\subsection{Interviews with the Schoolchildren}

Interviews are an important segment of data collection, in qualitative research. 
However, interviewing schoolchildren for scientific studies can be different and challenging compared to interviewing adults (Punch, 2002: p. 322; Yin, 2015: p. 63) [19] [21]. When interviewing schoolchildren, researchers must be more sensitive and grave than when conducting interviews with adults. Sharma (2008) [16] stated that the purpose of an interview is, "not to collect superficial detail about the interviewee but is rather to probe into the inner life of the interviewee", and thus requires in-depth analysis (p. 309). The importance of creating a relationship between the researcher and the participants cannot be overstated (Hemming, 2008: p. 154) [22]. The power differentials between the children and the researcher have to be considered and dealt with to increase confidence in the children's responses and eliminate the "teacher initiation-child response-teacher feedback process that children expect from adults" (Hemming, 2008: p. 154) [22]. When a proper understanding is created between the researcher and child, the research can more easily obtain intimate facts reflecting the child's viewpoint. Sharma (2008) [16] explained that interviews can also further the scope of a hypothesis as the child reveals more details about him- or herself (p. 310).

In a school setting with child respondents as interviewees, a semi-structured interview is more efficient than an unstructured one. Children are prone to distraction, but their wandering thoughts often raise interesting and unexpected points.

Much practical preparation is required before conducting an interview with schoolchildren. The environment is an important part of the interview. Interviews should take place in a quiet and free place with no disturbances or interruptions. However, the location should always be visible (Gill et al., 2008) [23]. Considering these recommendations, the interviews for my study were conducted in a free classroom adjacent to the administrative office which was clear visible from a distance; this also had minimal disturbances or interruptions. I conducted all the interviews individually with the help of the local female research assistant. The length of the interviews ranged from 20 to 40 minutes. A combination of both semi-structured and open-ended questionnaires was used as interview tools, and all the interviews were recorded using a digital voice recorder.

During one such interview, I observed that a girl was very nervous with her face being red. However, she was keen to participate in the interview and had completed all of the consent forms. When we were about to start the interview, she asked:

"Sir, why are you taking our interviews? Does it make any differences in our

life? If not, I will not participate in this program" (16-year-old girl from

Terai School)

I tried to convince her by explaining the purpose of my $\mathrm{PhD}$ study and the data collection procedure conducted in her school, but to no avail, as she withdrew from the process. I respected her decision and replaced her with another girl. Finding a replacement was quite challenging, particularly in the group of 
drop-outs as most of the schoolgirls who have dropped out from school have entered early marriages and have settled in their husbands' houses.

\subsection{Focus Group Discussion: Parents' View}

A Focus group discussion (FGD) is a methodological approach in qualitative research used to cover different points of view on issues at the same time. FGD is a unique method in which a group of people is informally interviewed, and questions on specific subjects are discusses to explore their perceptions, opinions, beliefs, and attitudes. Given the suitability of FGDs for this research, I conducted two FGDs with eight parents, including four fathers and four mothers, at both research sites. As it was the season for harvesting in Nepal, it is hard to arrange a time and a place for such informal interviews since most parents were working on the harvest. Therefore, I ultimately recruited parents using purposive sampling via 'snowball techniques' after multiple attempts.

Parents are potentially valuable sources of information regarding their children's schooling and its relationship with the social taboos of caste and gender inequality. Therefore, I conducted FGDs with parents to explore the relationship between schooling and social inequality of caste and gender from a different dimension. There is a big impact of parent involvement in education. The conversation between all the participants in FGD was considered the best part of the research process. Therefore, it is important to have an understanding of group dynamics, gender dynamics, and developmental stages within the groups (Darbyshire et al., 2005: p. 421) [24]. Darbyshire et al. (2005) [24] further explained that FGDs generate interactivity between the interviewer and interviewees. To increase interaction among participants, researchers should incorporate activities into the groups that "stimulate their thinking and discussion about the focus on physical activity and its associated people, places and spaces" (Darbyshire, 2005: p. 421) [24].

I warmed up the discussion with the parents by taking about very general issues, for example:

"Namaste sabaijanalai, Sanchai hunuhunchha? Aja ko yo vetghatkastolagekochha? Tapai ko ketaketiharulekastopadekachhan? (Good morning! Are you all fine? What do you think about today's meeting? How about your children's education?)"

This warm up discussion broke the ice to continue on to specific issues that I raised during the discussion. In semi-structured interviews, the direction of focus comes from the participants. The facilitators are non-directive because "the truth is not considered "out there" to be discovered but a phenomenon that emerges through dialogue or collective conversation" (Kamberelis \& Dimitriadis, 2014: p. XX) [25]. Considering the above, I acted as a facilitator during the FGD with local parents. I initiated the discussion by outlining the purpose of the study and the procedure of the FGD at hand and discussed how the participants could take turns in expressing their views. I tried to balance the power relation 
between the researcher and the participants, by means of integration with the villagers, both socially and culturally. After the successful completion of the discussion, I offered participants some local snacks (beaten rice with chicken curry) as a remuneration for their participation in the program, which is a common practice in rural Nepal.

\section{Discussion}

This article highlights some potential challenges carrying out ethnographic fieldwork in a Nepalese school. These include aspects of logistics, academic, social and cultural norms and values. Conducting research with schoolchildren is, in itself, a challenging task, particularly in Nepal, where social and cultural issues are given a higher priority in the society over other aspects. The inclusion of schoolchildren from the socially excluded community group, Dalit, as research participants for this study, rendered it to be even more challenging due to the existing caste and gender-based discrimination within the Nepalese society. However, children can demonstrate their innate abilities when a researcher adopts child-centered strategies, which take the cognitive, communicative, and social needs of children into account (Birbeck \& Drummond, 2007) [26]. In keeping with this approach, I offered the opportunity for all the children to talk freely and comfortably on the issues that I raised during the conversation. However, ethical issues may arise from qualitative methods of inquiry. Birbeck \& Drumond (2007) [26] revealed that one researcher while conducting focus group interviews, was only required to intervene in instances where physical (as opposed to psychological or emotional) harm occurred in keeping with the rules of that particular nation. In such situations, the researcher is left to decide between ensuring the integrity and validity of their data and protecting the safety of the children.

Power presents another challenge in research with child respondents. Hemming (2000) [22] explained that power involves a shifting relationship between the researcher and the researcher's subjects. Birbeck and Drumond (2007) [26] explained that, when participant observation is used to gather data from children respondents, the researcher has to be immersed in the culture, but is often immersed in the adult culture instead. "However, if childhood is thought of as a culture, there are certain problems with researcher immersion in a cohort of children. An adult stands out physically." (Bribeck and Drumond 2007: p. 27) [26]. Bribeck and Drumond (2007) [26] noted that children see adults being present to ensure their safety and order. This is demonstrated in the work of Darbyshire et al. (2005) [24], where the children of the focus groups were encouraged to engage in playful activities to help them understand that the events taking place were not classroom activities and that the researcher was not there to control them. This approach contributed to creating more openness and discussion in the focus groups compared to the hesitancy noticed from the children otherwise. Darbyshire et al. (2005) [24] recommend that a researcher should adopt flexibility and creativity during data collection. An investigator has to 
"modify and adapt elements of the study as it progressed in the light of the children's responses" (Darbyshire et al., 2005: p. 428) [24].

As discussed earlier, perception and memory are subjective responses, particularly in children (Spencer \& Flin, 1993) [27]. For this reason, researchers should arrange a supportive environment for children. Children are more susceptible to suggestion than adults, and this creates an obstacle for the researchers (Spencer \& Flin, 1993) [27]. Darbyshire et al. (2005) [24] noted that the greatest amount of accurate information could be obtained from a child immediately after an event. In the end, it is important for the researcher to understand the events that a child perceives as critical to his or her central being (Darbyshire et al., 2005) [24].

The analysis, finally, demonstrates the different methods used by a male researcher who was from the same community group as the researched school children, and the numerous barriers encountered in conducting the research, both socially and culturally, particularly in Nepalese context.

\section{Conclusions}

In this article, I have focused on the logistic, academic, and social challenges that impacted in my scholarly inquiry into school and society in rural Nepal. In the past, social researchers have used several qualitative methods of collecting data with the aim of understanding children in their social contexts. The methods highlighted in this paper include participant observation, field notes, individual interviews, and focus group discussions. These methods presented various challenges for the researcher that broadly highlights two main aspects. Firstly, being a male researcher from the same community as the younger female participants of my research, addressing issues of gender and caste inequality and schooling was challenging in the culturally rigid society of Nepal. Secondly, both research sites were located a long distance from the district headquarters which presented problems of accessibility in addition to various associated logistic, mechanical, and technical difficulties.

Research which focuses on schoolchildren requires more creativity and flexibility from both researchers and participants. Also, other contributory factors such as the social contexts, the culture, religions, language and the regions also play significant roles in the research process, particularly when conducting research with schoolchildren. In Nepal, children are traditionally excluded from participating in social activities due to different social values and cultural norms.

Birbeck and Drummond (2007) [26] argued that, if researchers are to work with children, they must employ methodologies that support children's intellectual and social abilities. The methodologies must allow the researchers to uphold their social and ethical obligations while protecting children from physical, psychological, or emotional threats. Considering Birbeck and Drummond's (2007) [26] recommendations, all participants (schoolchildren) in this research were provided with a free and safe environment, i.e. a separate, designated classroom within their schools. I noticed that most of the participants expressed their feelings 
and opinions easily and clearly. In some instances, such results are not easily achieved due to the rules and regulations surrounding research that involve children. Determining the best methodological approach is thus left to the sociologist's discretion.

Finally, the analysis demonstrates that researching schoolchildren from the socially excluded community group, Dalit, in Nepal, is challenging both logistically, culturally, and socially. This is because the Dalit community predominantly lives in the periphery of the countryside and is excluded from the social mainstream, resulting in their voices being hardly heard on any occasion.

\section{References}

[1] England, K. (1994) Getting Personal: Reflexivity, Positionality, and Feminist Research. The Professional Geographer, 46, 80-89.

https://doi.org/10.1111/j.0033-0124.1994.00080.x

[2] Deatrick, J. and Faux, S. (1991) Conducting Qualitative Studies with Children and Adolescents. In: Morse, J.M., Ed., Qualitative Nursing Research: A Contemporary Dialogue, Sage Publication, Newbury Park, 203-223. https://doi.org/10.4135/9781483349015.n24

[3] Scott, J. (2000) Children as Respondents: The Challenge for Quantitative Methods. In: Christensen, P. and James, A., Eds., Research with Children: Perspectives and Practices, Falmer Press, London, Chapter 5.

[4] Mahat, I. (2011) Doing Fieldwork in Development Research: Issues in Applications of Methodologies. https://www.academia.edu/463154/Doing_Fieldwork in Development Research Is sues in Applications of Methodologies

[5] Jagaran Media Center (2012) Dalit Women and Their Major Issues. Kathmandu. http://www.jagarannepal.org/dalit-women-and-their-major-issues

[6] UNESCO (2011) National Literacy Campaign. http://www.unesco.org/uil/litbase/?menu=14\&programme=122

[7] Zavella, P. (1996) Feminist Insider Dilemmas: Constructing Ethnic Identity with Chicana Informants. In: Carmen, D.D. and Diane, W.L., Eds., Feminist Dilemmas in Fieldwork, Westview Press, CO, 138-139.

[8] Stash, S. and Hannum, E. (2001) Who Goes to School? Educational Stratification by Gender, Caste, and Ethnicity in Nepal. Comparative Education Review, 45, 354-378. https://doi.org/10.1086/447676

[9] Bishwokarma, D. (2010) Caste Based Discrimination in School: A Study of Dalits in Ramechhap. An unpublished M.Phil.in education thesis, Kathmandu University, Kathmandu, Nepal

[10] Wilkinson, S. and Kitzinger, C., Eds. (1996) Representing the Other: A Feminism and Psychology Reader. Sage, London.

[11] Denzin, N. and Lincoln, Y. (2000) The Discipline and Practice of Qualitative Research. In: Denzin, N.K. and Lincoln, Y.S., Eds., Handbook of Qualitative Research, Sage, Thousand Oaks, 1-32.

[12] Clark, C. (2011) In a Younger Voice: Doing Child-Centered Qualitative Research. Oxford University Press, New York, 3-25.

[13] Woods, P. (1999) Successful Writing for Qualitative Researchers. Routledge, London. 
[14] Kanyal, M., Luff, P., Cooper, L. and Webster, R. (2014) Participatory Approaches in Research Involving Children. In: Kanyal, M., Ed., Children's Rights 0-8: Promoting Participation in Education and Care, Routledge, New York, 116-150.

[15] Hume, L. and Mulcock, J. (Eds) (2004) Introduction: Awkward Spaces, Productive Places. In: Hume, L., Mulcock, J., Hume, L. and Mulcock, J., Eds., Anthropologists in the Field: Cases in Participant Observation, Columbia University Press, New York, 9-28. http://www.jstor.org/stable/10.7312/hume13004.4

[16] Sharma, R. (2008) Sociological Methods and Techniques. Atlantic Publishers \& Distributors, New Delhi.

[17] Corsaro, W. and Fingerson, L. (2006) Development and Socialization in Childhood. In: Delamater, J., Ed., Handbook of Social Psychology, Springer, Berlin, 125-155. https://doi.org/10.1007/0-387-36921-X 6

[18] Dunn, J. (2005) Naturalistic Observations of Children and Their Families. In: Hogan, S.G., Ed., Researching Children's Experience, Sage, Thousand Oaks, 87-101.

[19] Punch, S. (2002) Research with Children: The Same or Different from Research with Adults? Childhood, 9, 321-341. https://doi.org/10.1177/0907568202009003005

[20] Spear, C.F., Strickland-Cohen, M.K., Romer, N. and Albin, R.W. (2013) An Examination of Social Validity within Single-Case Research with Students with Emotional and Behavioral Disorders. Remedial and Special Education, 34, 357-370. https://doi.org/10.1177/0741932513490809

[21] Yin, R. (2015) Qualitative Research from Start to Finish. Guilford Publications, New York.

[22] Hemming, P. (2008) Mixing Qualitative Methods in Children's Geographies. Area, 40, 152-162. https://doi.org/10.1111/j.1475-4762.2008.00798.x

[23] Gill, P., Steward, K., Treasure, E. and Chadwick, B. (2008) Conducting Qualitative Interviews with School Children in Dental Research. British Dental Journal, 204 371-374. https://doi.org/10.1038/sj.bdj.2008.245

[24] Darbyshire, P., MacDougall, C. and Schiller, W. (2005) Multiple Methods in Qualitative Research with Children: More Insight or Just More? Qualitative Research, 5, 417-436. https://doi.org/10.1177/1468794105056921

[25] Dimitriadis, G. and Kamberelis, G. (2014) Focus Group Research: Retrospect and Prospect. In: Leavy, P., Ed., The Oxford Handbook of Qualitative Research, Oxford University Press, New York, 315-320.

[26] Birbeck, D. and Drummond, M. (2007) Research with Young Children: Contemplating Methods and Ethics. Journal of Education Inquiry, 7, 21-28.

[27] Flin, R. and, Spencer, J. (1993) The Evidence of Children: The Law and Psychology. 2nd Edition, Blackstone Press Ltd., London. 
Submit or recommend next manuscript to SCIRP and we will provide best service for you:

Accepting pre-submission inquiries through Email, Facebook, LinkedIn, Twitter, etc. A wide selection of journals (inclusive of 9 subjects, more than 200 journals)

Providing 24-hour high-quality service

User-friendly online submission system

Fair and swift peer-review system

Efficient typesetting and proofreading procedure

Display of the result of downloads and visits, as well as the number of cited articles Maximum dissemination of your research work

Submit your manuscript at: http://papersubmission.scirp.org/

Or contact jss@scirp.org 